\title{
Reduced Raf-1 kinase inhibitor protein expression predicts less favorable outcomes in patients with hepatic colorectal metastasis
}

\author{
HYUN-SOO KIM ${ }^{1}$, SUN JIN PARK ${ }^{2}$, KIL YEON LEE ${ }^{2}$, YONG-KOO PARK $^{1}$ and YOUN WHA KIM ${ }^{1}$ \\ Departments of ${ }^{1}$ Pathology and ${ }^{2}$ Surgery, Graduate School of Medicine, Kyung Hee University, Seoul, Republic of Korea
}

Received March 5, 2012; Accepted April 18, 2012

DOI: $10.3892 /$ or.2012.1797

\begin{abstract}
Reduced expression of Raf-1 kinase inhibitor protein (RKIP) has been documented in a number of human malignancies, including colorectal carcinoma (CRC). However, despite the importance of hepatic colorectal metastasis (HCM) for the prognosis of CRC patients, no studies have been conducted regarding RKIP expression in HCM tissues or its prognostic significance. The aim of this study was to clarify the relationship between reduced RKIP expression and HCM and to identify independent predictors for recurrent HCM, which will ultimately help identify patients at high risk of developing metastatic recurrence. An immunohistochemical study of RKIP expression was performed using primary CRC and/or corresponding HCM tissue samples obtained from 117 patients. Forty-nine of these patients did not harbor HCM and 68 harbored HCM. RKIP expression was reduced in $24.5 \%$ (12/49) of CRCs without HCM, 47.1\% (32/68) of CRCs with HCM and $67.6 \%$ (46/68) of HCM. This distribution of RKIP downregulation was statistically significant. RKIP expression was found to independently predict recurrent HCM, with a higher relative risk (6.661) compared to that of nodal metastasis (4.690). A reduction of RKIP expression in HCM was a significant predictor of poor prognosis. The median survival of patients with reduced RKIP expression was 35 months, compared with more than 10 years in patients with positive RKIP expression. Multivariate survival analysis demonstrated that RKIP expression in HCM was an independent predictor of overall survival, with a hazard ratio of 5.161, a value comparable to the risk associated with advanced TNM stage (5.247). We demonstrated that a reduction of RKIP expression in HCM had an independent predictive value for metastatic recurrence and less favorable clinical outcomes in patients with HCM. Our results strongly suggest that patients harboring HCM with reduced RKIP expression require careful monitoring after
\end{abstract}

Correspondence to: Dr Youn Wha Kim, Department of Pathology, Graduate School of Medicine, Kyung Hee University, 1 Hoegi-dong, Dongdaemun-gu, 130-702 Seoul, Republic of Korea

E-mail: kimyw@khu.ac.kr

Key words: Raf kinase inhibitor protein, colorectal carcinoma, liver, metastasis, recurrence hepatic resection to detect potentially resectable metastatic recurrences.

\section{Introduction}

Colorectal carcinogenesis is a complex multistep process involving progressive disruption of intestinal epithelial cell proliferation, apoptosis, differentiation and survival mechanisms (1). The extracellular signal-regulated kinase (ERK) pathway is one of the most important pathways for intestinal cell proliferation and differentiation. In this pathway, ERK is activated upon phosphorylation by mitogen-activated protein kinase/ERK kinase (MEK), which itself is activated when phosphorylated by Raf- 1 . There is growing evidence that activation of the Raf-1/MEK/ERK signaling pathway is involved in the pathogenesis, progression and oncogenic behavior of human colorectal carcinoma (CRC) (2). The activated ERK pathway in CRC plays a role in cell proliferation through dysregulation of the cell cycle, angiogenesis through enhancing the expression of vascular endothelial growth factor and cell migration and invasion through induction of proteolytic enzymes, such as matrix metalloproteinases (3).

Raf-1 kinase inhibitory protein (RKIP), also known as phosphatidylethanolamine-binding protein 1 , was originally identified as an endogenous inhibitor of Raf-1, and it negatively regulates the Raf-1/MEK/ERK signaling pathway (4). RKIP suppresses the metastatic spread of tumor cells; moreover, reduced expression of RKIP is observed in a number of human malignancies (5). In addition to its pivotal role in regulating cell differentiation, cycle and migration, evidence also suggests that RKIP potentiates the apoptosis of tumor cells induced by chemotherapy or radiotherapy $(6,7)$. In vitro studies demonstrated that ectopic RKIP overexpression sensitizes DNA-damaging agent-resistant carcinoma cells to undergo apoptosis and can allow tumor cells to be eliminated by host cytotoxic lymphocytes $(6,8)$. Furthermore, restoration of RKIP expression in metastatic prostate carcinoma cells is associated with decreased in vitro cell invasion, decreased development of lung metastases in vivo and decreased vascular invasion in the primary tumor (9). These data suggest that the attenuation of RKIP in tumor cells represents an underlying molecular mechanism of tumor progression and metastasis.

The liver is the most common organ of distant metastases from CRC. Untreated patients with hepatic colorectal metastasis (HCM) have poor prognoses, with a median survival of 
6-12 months. Chemotherapy modestly extends median survival to $12-18$ months, but a cure remains unlikely (10). In contrast, surgical resection of HCM can offer long-term survival and cure in patients with HCM; a 5-year survival rate of 25-39\% after hepatic resection has been reported (11). Therefore, hepatic resection currently represents the best potentially curative treatment for HCM. Unfortunately, however, 60-70\% of patients undergoing hepatic resection for HCM will develop recurrences of the disease, most of which are identified in the first 12-18 months postoperatively (12). Of these, one third will have recurrent metastases isolated to the liver. Since hepatic resection has become safer through improvements in surgical techniques and perioperative management, repeat hepatic resection is more frequently performed in patients with isolated HCM (13). Repeat hepatic resection for recurrent HCM in carefully selected patients appears warranted in view of reasonable survival expectations that approach that of single hepatic resection (14). In this regard, there is a need for criteria based on biological determinants for the stratification of patients better and earlier according to their risk of recurrence and survival and, consequently, for the selection of patients who may benefit from repeat hepatic resection.

The aim of this study was to evaluate RKIP expression in HCM tissues and to determine whether there is an association between RKIP expression and clinicopathological characteristics and outcome of patients with HCM. In addition, independent predictors for recurrent HCM and their combinations were identified, leading to the identification of patients at high risk of developing metastatic recurrence.

\section{Materials and methods}

Patients and tissue specimens. Human CRC tissue samples were obtained from 117 consecutive patients who underwent surgery at the Kyung Hee University Hospital, including 68 patients with HCM and 49 patients without HCM. In the patients with HCM, the corresponding metastatic tissue samples from the same patient were also examined. All the 68 patients with HCM had to meet the following criteria to be considered a candidate for hepatic resection with intent for cure: i) no signs of extrahepatic metastases found in preoperative studies, including chest roentgenography, abdominal ultrasonography and abdominopelvic computed tomography; ii) HCMs such that adequate-sized, well-vascularized hepatic remnants would remain after resection; iii) the patient was medically fit for major hepatic resection. Only patients whose metastases were resectable on presentation were included.

Two independent pathologists reviewed all hematoxylin and eosin-stained slides and selected the most representative slide from each case to perform immunohistochemical staining. Clinicopathological data, including age; gender; location and size of the primary tumor; histological grade; pathological tumor stage (pT); the presence of nodal metastasis and/or HCM; local recurrence; TNM stage; the presence of lymphovascular invasion; size, number and distribution of the metastatic tumor; and postoperative follow-up, were assessed. All tumors were assessed for histological grade according to the World Health Organization classification (15), and were postoperatively staged according to the seventh edition of the
American Joint Committee on Cancer staging system (16). Research protocols for the use of human tissue were approved by and conducted in accordance with the polices of the Institutional Review Board at Kyung Hee University Hospital. Informed consent was obtained from all subjects.

Immunohistochemistry. RKIP expression was assessed by immunohistochemistry using the Bond Polymer Intense Detection System (Vision BioSystems, Mount Waverley, VIC, Australia) according to the manufacturer's instructions. Briefly, 4- $\mu \mathrm{m}$ sections of formalin-fixed, paraffin-embedded tissue were deparaffinized with Bond Dewax Solution (Vision BioSystems), and an antigen retrieval procedure was performed using Bonder solution (Vision BioSystems) for $30 \mathrm{~min}$ at $100^{\circ} \mathrm{C}$. Endogenous peroxidases were quenched by incubation with hydrogen peroxide for $5 \mathrm{~min}$. The sections were incubated for $15 \mathrm{~min}$ at ambient temperature with a rabbit polyclonal antiRKIP antibody (1:200; Santa Cruz Biotechnology, Santa Cruz, CA, USA). The biotin-free polymeric horseradish peroxidaselinker antibody conjugate system was used in the Bond-maX ${ }^{\mathrm{TM}}$ automatic slide stainer (Vision BioSystems), and visualization was performed by 3,3'-diaminobenzidine (DAB) solution [1 mM DAB, $50 \mathrm{mM}$ Tris-HCl buffer $(\mathrm{pH}$ 7.6) and $0.006 \%$ $\mathrm{H}_{2} \mathrm{O}_{2}$. Nuclei were counterstained with hematoxylin. Slides were subsequently dehydrated following a standard procedure and sealed with coverslips. In order to minimize interassay variation, positive and negative control samples were included in each run. The positive control sample was normal colonic mucosa, and the negative control was prepared by substituting non-immune serum for antibody.

Evaluation of immunohistochemical staining. Immunohistochemical RKIP expression was analyzed with a semi-quantitative scoring method, as described in previous studies (17-22). The score is the sum of the percentage of positive tumor cells $(0$, none; $1,<25 \% ; 2,25-49 \%$; and $3, \geq 50 \%)$ and the staining intensity $(0$, negative; 1 , weak; 2 , moderate; and 3 , strong). Specimens with sums between 0 and 2 were scored as negative, sums of 3 and 4 were scored as weakly positive, and sums of 5 and 6 were scored as positive. All slides were examined and scored by two independent pathologists, who were blinded to the clinicopathological data and patient identity. Disagreements between the two pathologists were resolved by consensus.

Statistical analysis. The $\chi^{2}$ test or Fisher's exact test was performed to compare RKIP expression between each pair of groups and to determine whether RKIP expression is associated with the clinicopathological characteristics. Multivariate logistic regression analysis with a backward stepwise elimination method was used to identify independent predictors for recurrent HCM. The logistic regression equation also indicated the probability of developing recurrent HCM based on the combination of independent predictors. Univariate and multivariate survival analyses were used to examine the prognostic significance of RKIP expression. Cancer-specific survival was defined as the interval from surgery to the death of the patient due to CRC. Loss to follow-up, death from a cause other than carcinoma and survival until the end of the follow-up period were considered censoring events. The 


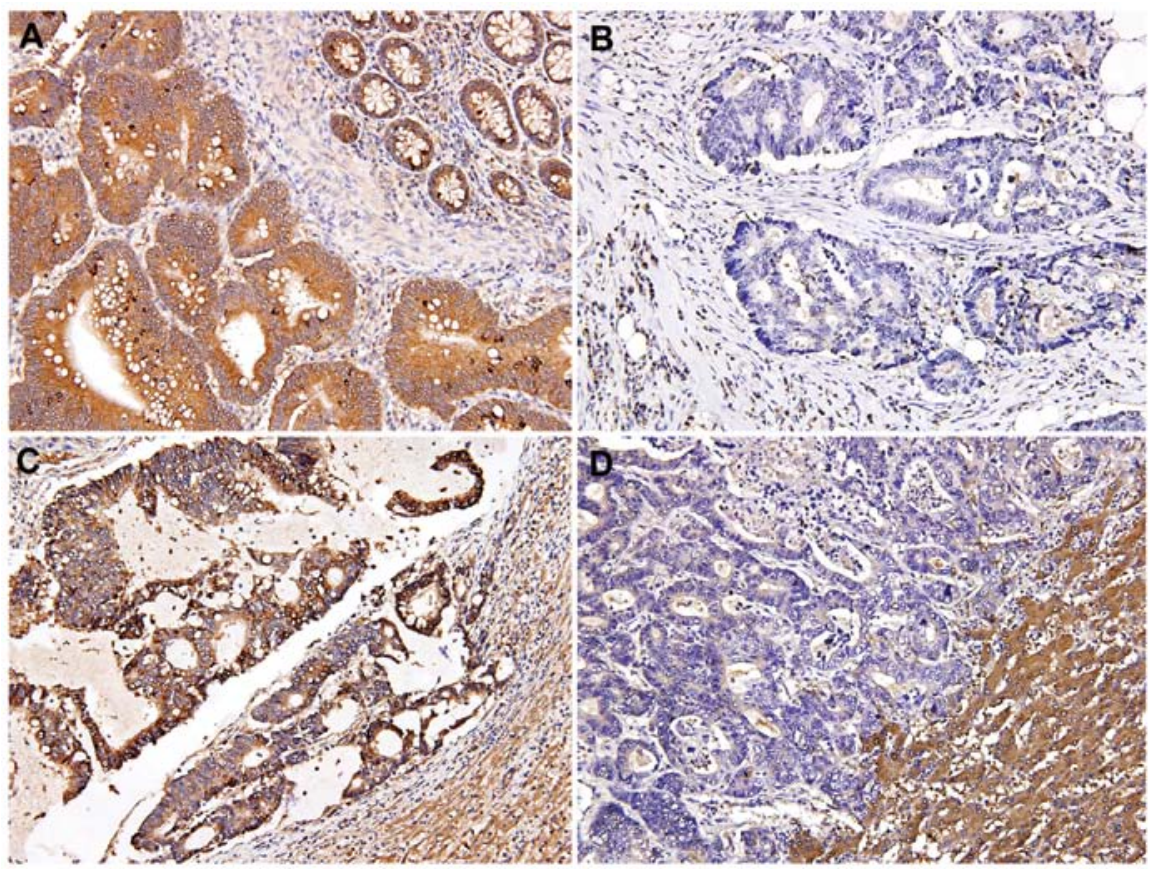

Figure 1. RKIP immunoreactivity in CRC and HCM. (A) Positive RKIP immunoreactivity in CRC. Localization of RKIP in the cytoplasm of peritumoral colonic epithelia (right upper corner). (B) Negative RKIP immunoreactivity in CRC. (C) Positive and (D) reduced RKIP immunoreactivity in HCM. Adjacent hepatocytes (right lower corner) serve as a positive control (polymer method; original magnification, x200).

survival curves were drawn according to the Kaplan-Meier method and differences were analyzed by applying the logrank test for univariate survival analysis. Multivariate survival analysis was performed using the Cox proportional hazard model (95\% confidence interval) with a backward stepwise elimination method. All covariates with statistical significance in univariate analysis were entered into the multivariate analysis. The least significant covariates were then removed from the model by backward stepwise elimination. Statistical analyses were performed using SPSS version 15.0 (SPSS Inc., Chicago, IL, USA). Statistical significance was defined as a P-value of $<0.05$.

\section{Results}

Patient demographics and clinicopathological characteristics. The median age of patients was 61 (range, 33-81); 51.3\% (60/117) were 61 or older. There were 77 men and 40 women. Of 68 patients with HCM, 40 (58.8\%) patients had died at the time of last follow-up, with the median time to death from hepatic resection of 36 months (range 5-144 months). Median follow-up of survivors was 44 months. Other baseline clinicopathological characteristics of the 117 CRC patients are shown in Table I.

Immunohistochemical RKIP expression in CRC and HCM tissues and its association with clinicopathological characteristics. RKIP immunoreactivity was found to be predominantly cytoplasmic, although weak nuclear staining was noted in a few cells. RKIP expression was observed in tumor cells and in normal epithelial cells of the peritumoral colonic mucosa. RKIP expression was not detectable in the extracellular matrix or in the connective tissues.
Intense RKIP immunostaining was observed in normal colonic epithelia (Fig. 1A), whereas RKIP expression was reduced in tumor tissue, as expected based on results from previous studies $(18,23)$. In CRC without HCM cases, RKIP expression was positive in $75.5 \%$ (37/49; Fig. 1A), weakly positive in $20.4 \%$ (10/49) and negative in $4.1 \%$ (2/49) of the samples. In CRC with HCM cases, RKIP expression was positive in $52.9 \%(36 / 68)$, weakly positive in $41.2 \%$ (28/68) and negative in 5.9\% (4/68; Fig. 1B) of the samples. This distribution of RKIP downregulation was statistically significant $(\mathrm{P}=0.028)$. Furthermore, in HCM cases, RKIP expression was positive in $32.4 \%$ (22/68; Fig. 1C), weakly positive in $30.8 \%$ (21/68) and negative in $36.8 \%$ (25/68; Fig. 1D) of the samples. This decrease of RKIP expression in HCM cases compared with the corresponding primary CRC with HCM was also statistically significant $(\mathrm{P}<0.001)$, suggesting that the metastatic process in CRC involves a reduction of RKIP expression. None of the clinicopathological characteristics was associated with RKIP expression in HCM (Table II).

Association of clinicopathological characteristics and RKIP expression with recurrent HCM. The presence of nodal metastasis $(\mathrm{P}=0.015)$ and vascular invasion $(\mathrm{P}=0.045)$, a higher number $(\mathrm{P}=0.034)$ and bilobar distribution $(\mathrm{P}=0.048)$ of metastatic tumor and reduced RKIP expression $(\mathrm{P}=0.022)$ were associated with the recurrence of HCM (Table III). Of these five covariates entered into multivariate logistic regression analysis, nodal metastasis $(\mathrm{P}=0.029)$, number of metastatic tumor $(\mathrm{P}=0.001)$ and RKIP expression $(\mathrm{P}=0.010)$ were found to independently predict recurrent HCM. Interestingly, reduction of RKIP expression showed a higher relative risk of recurrent HCM (6.661) than that of nodal metastasis (4.690). In addition, when combining the three independent predictors, 
Table I. Baseline clinicopathological characteristics of 117 CRC patients.

Characteristics
Characteristics of primary tumor
Age

Range (median; years-old)

33-81 (61)

Female

Location of primary tumor

Right colon

Cecum

Ascending colon

Transverse colon

Left colon

Descending colon

Sigmoid colon

Rectosigmoid colon

Rectum

Size of primary tumor $(\mathrm{cm})$

$\geq 5$

$<5$

Histological grade

Well

Moderate

Poor

9

26

3

6

28

6

39

63

54

16

98

3

Pathological tumor stage

pT3

pT4

105

12

Nodal metastasis

Present

Absent

HCM

Present

Absent

TNM stage

II

III

IV

Lymphatic invasion

Present

Absent

Vascular invasion

Present

Absent

Characteristics of metastatic tumor

Size of metastatic tumor $(\mathrm{cm})$

$$
\geq 2.5
$$

$<2.5$

No. of metastatic tumors

$$
1
$$

51
66

12

105
77

40

CRC without HCM $(n=49)^{a}$

CRC with HCM $(\mathrm{n}=68)^{\mathrm{a}}$

39-81 (65)

33-76 (57)

$31(63.3)$

46 (67.6)

18 (36.7)

$22(32.4)$

$6(12.2)$

3 (4.4)

$12(24.5)$

$14(20.6)$

2 (4.1)

1 (1.5)

$3(6.1)$

$14(28.6)$

3 (4.4)

1 (2.0)

$11(22.4)$

14 (20.6)

5 (7.4)

28 (41.2)

$31(63.3)$

32 (47.1)

36 (52.9)

2 (2.9)

64 (94.1)

2 (2.9)

34 (69.4)

1 (2.0)

56 (82.4)

12 (17.6)

49 (72.1)

$0(0.0)$

19 (27.9)

$49(100.0)$

44 (64.7)

24 (35.3)

$49(100.0)$

9 (13.2)

$49(100.0)$

19 (27.9)

$0(0.0)$

40 (58.8)

$0(0.0)$

27 (39.7)

41 (60.3)

$0(0.0)$

12 (17.6)

49 (100.0)

$56(82.4)$

31 (45.6)

37 (54.4)

Not available

38 (55.9)

Not available

18 (26.5) 
Table I. Continued.

\begin{tabular}{lccc}
\hline Characteristics & Total $(\mathrm{n}=117)^{\mathrm{a}}$ & CRC without HCM (n=49) & CRC with HCM $(\mathrm{n}=68)^{\mathrm{a}}$ \\
\hline No. of metastatic tumors & & & \\
3 & 5 & Not available & $5(7.4)$ \\
$\geq 4$ & 7 & Not available & $7(10.3)$ \\
Distribution of metastatic tumor(s) & & & \\
$\quad$ Bilobar & 19 & Not available & $19(27.9)$ \\
Unilobar & 49 & Not available & $49(72.1)$ \\
Recurrent HCM after hepatic resection & & & \\
Present & 44 & Not available & $44(64.7)$ \\
Absent & 24 & Not available & $24(35.3)$ \\
\hline
\end{tabular}

${ }^{\mathrm{a} D}$ Data are $\mathrm{n}(\%)$, unless otherwise indicated.

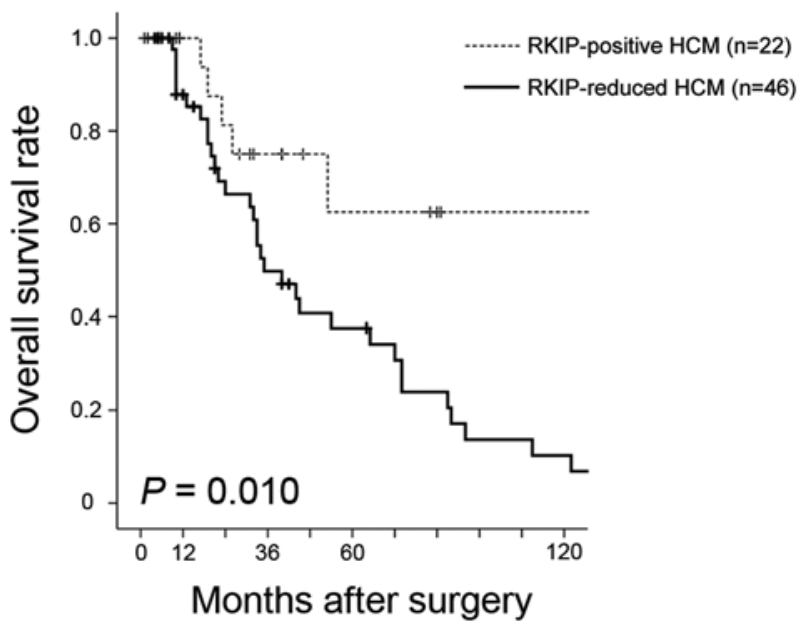

Figure 2. Kaplan-Meier curves for OS in relation to RKIP expression in HCM, indicated by the solid line in HCM patients with negative or weakly positive RKIP expression and by the dotted line in HCM patients with positive RKIP expression.

the subgroup of node-negative patients with multiple HCMs and reduced RKIP expression had the greatest probability of developing recurrent HCM (96\%; Table IV). Node-positive patients with single HCM were divided into two subgroups according to RKIP expression status; the patients with reduced RKIP expression had a much higher probability of developing recurrent HCM (74\%) than patients with positive RKIP expression (39\%). Similarly, the node-negative/multiple HCMs/ RKIP-reduced subgroup had a higher probability of developing recurrent HCM (84\%) than the node-negative/multiple HCMs/RKIP-positive subgroup (52\%). The probability of developing metastatic recurrence in the node-negative/single HCM/RKIP-reduced subgroup (48\%) was also higher than in the node-negative/single HCM/RKIP-positive subgroup (11\%).

Influence of reduced RKIP expression on survival. Adequate clinical follow-up information was available for all $68 \mathrm{HCM}$ patients. Univariate analysis for survival revealed that an advanced TNM stage $(\mathrm{P}=0.008)$, the presence of lymphatic $(\mathrm{P}=0.008)$ and vascular invasion $(\mathrm{P}=0.028)$, a higher number
$(\mathrm{P}=0.001)$ and bilobar distribution $(\mathrm{P}=0.047)$ of metastatic tumor, the recurrence of HCM $(\mathrm{P}=0.001)$ and reduced RKIP expression $(\mathrm{P}=0.009)$ were significant predictors of poor prognosis (Table V). The median survival of patients with reduced RKIP expression was 35 months, compared with $>10$ years in patients with positive RKIP expression (Fig. 2). KaplanMeier plots showed that patients with RKIP-positive HCM had relatively stable survival rates of $75.0 \%$ between two and four years after surgery and survival of $62.5 \%$ after four years. In contrast, patients with reduced RKIP expression in HCM experienced a steady decline in survival during the entire observation period. The 1-, 3- and 5-year survival rates were 87.8, 49.8 and $37.6 \%$ for patients with RKIP-reduced HCM and $100.0,75.0$ and $62.5 \%$ for patients with RKIP-positive HCM, respectively (Fig. 2).

Analysis by a multivariate Cox proportional hazard model was performed using TNM stage, lymphatic invasion, number and distribution of metastatic tumor, RKIP expression, vascular invasion and recurrent HCM as covariates. The first five of these covariates were independent prognostic factors, which influenced survival (Table V). This analysis also demonstrated that reduced RKIP expression in HCM was associated with a significant hazard ratio of 5.161, a value comparable to the risk associated with an advanced TNM stage (5.247).

\section{Discussion}

RKIP is a widely expressed and highly conserved cytoplasmic protein, which is reduced in a number of human malignancies, including malignant melanoma and carcinomas of the prostate, breast, liver, gallbladder, pancreas, extrahepatic bile duct, stomach, ovary, uterine cervix and nasopharynx $(19,20,22,24-33)$. In these tumors, reduced RKIP expression is associated with an advanced stage, lymphovascular invasion, metastasis and recurrence and/or poor patient outcome. This suggests that RKIP serves as a prognostic marker and has potential as a molecular determinant of invasion and metastasis. Recently, some investigators have also reported reduction of RKIP expression in CRC and an association between reduced RKIP expression and the presence of nodal and distant metastases, metastatic recurrence and lower 
Table II. Relationships between RKIP expression in HCM and clinicopathological characteristics.

\begin{tabular}{|c|c|c|c|c|}
\hline \multirow[b]{2}{*}{ Characteristics } & \multicolumn{3}{|c|}{ RKIP expression ${ }^{\mathrm{a}}$} & \multirow[b]{2}{*}{ P-value } \\
\hline & Negative & Weakly positive & Positive & \\
\hline \multicolumn{5}{|l|}{ Age (years) } \\
\hline$\geq 61$ & $12(48.0)$ & $9(42.9)$ & $9(40.9)$ & \multirow[t]{2}{*}{0.624} \\
\hline$<61$ & $13(52.0)$ & $12(57.1)$ & $13(59.1)$ & \\
\hline \multicolumn{5}{|l|}{ Gender } \\
\hline Male & $16(64.0)$ & $15(71.4)$ & $15(68.2)$ & \multirow[t]{2}{*}{0.750} \\
\hline Female & $9(36.0)$ & $6(28.6)$ & $7(31.8)$ & \\
\hline \multicolumn{5}{|c|}{ Location of primary tumor } \\
\hline Right colon & $8(32.0)$ & $3(14.3)$ & $7(31.8)$ & \multirow[t]{2}{*}{0.946} \\
\hline Left colon & $17(68.0)$ & $18(85.7)$ & $15(68.2)$ & \\
\hline \multicolumn{5}{|c|}{ Size of primary tumor $(\mathrm{cm})$} \\
\hline$\geq 5$ & $13(54.2)$ & $10(45.5)$ & $9(40.9)$ & \multirow[t]{2}{*}{0.452} \\
\hline$<5$ & $12(48.0)$ & $11(52.4)$ & $13(59.1)$ & \\
\hline \multicolumn{5}{|c|}{ Histological grade } \\
\hline Well & $0(0.0)$ & $1(4.8)$ & $1(4.5)$ & \multirow[t]{3}{*}{0.550} \\
\hline Moderate & $24(96.0)$ & $20(95.2)$ & $20(90.9)$ & \\
\hline Poor & $1(4.0)$ & $0(0.0)$ & $1(4.5)$ & \\
\hline \multicolumn{5}{|c|}{ Pathological tumor stage } \\
\hline pT3 & $21(84.0)$ & $19(90.5)$ & $16(72.7)$ & \multirow[t]{2}{*}{0.336} \\
\hline pT4 & $4(16.0)$ & $2(9.5)$ & $6(27.3)$ & \\
\hline \multicolumn{5}{|c|}{ Nodal metastasis } \\
\hline Present & $19(76.0)$ & $13(61.9)$ & $17(77.3)$ & \multirow[t]{2}{*}{0.958} \\
\hline Absent & $6(24.0)$ & $8(38.1)$ & $5(22.7)$ & \\
\hline \multicolumn{5}{|l|}{ TNM stage } \\
\hline II & $4(16.0)$ & $2(9.5)$ & $3(13.6)$ & \multirow[t]{3}{*}{0.898} \\
\hline III & $5(20.0)$ & $8(38.1)$ & $6(27.3)$ & \\
\hline IV & $16(64.0)$ & $11(52.4)$ & $13(59.1)$ & \\
\hline \multicolumn{5}{|c|}{ Lymphatic invasion } \\
\hline Present & $9(36.0)$ & $7(33.3)$ & $11(50.0)$ & \multirow[t]{2}{*}{0.344} \\
\hline Absent & $16(64.0)$ & $14(66.7)$ & $11(50.0)$ & \\
\hline \multicolumn{5}{|c|}{ Vascular invasion } \\
\hline Present & $4(16.0)$ & $3(14.3)$ & $5(22.7)$ & \multirow[t]{2}{*}{0.561} \\
\hline Absent & $21(84.0)$ & $18(85.7)$ & $17(77.3)$ & \\
\hline \multicolumn{5}{|c|}{ Size of metastatic tumor $(\mathrm{cm})$} \\
\hline$\geq 2.5$ & $9(36.0)$ & $11(52.4)$ & $11(50.0)$ & 0.327 \\
\hline$<2.5$ & $16(64.0)$ & $10(47.6)$ & $11(50.0)$ & \\
\hline No. of metastat & & & & \\
\hline 1 & $14(56.0)$ & $9(42.9)$ & $15(68.2)$ & 0.675 \\
\hline 2 & $8(32.0)$ & $6(28.6)$ & $4(18.2)$ & \\
\hline 3 & $0(0.0)$ & $4(19.0)$ & $1(4.5)$ & \\
\hline$\geq 4$ & $3(12.0)$ & $2(9.5)$ & $2(9.1)$ & \\
\hline Distribution of & & & & \\
\hline Unilobar & $7(28.0)$ & $8(38.1)$ & $4(18.2)$ & 0.485 \\
\hline Bilobar & $18(72.0)$ & $13(61.9)$ & $18(81.8)$ & \\
\hline
\end{tabular}

${ }^{\mathrm{a} D a t a}$ are $\mathrm{n}(\%)$, unless otherwise indicated. 
Table III. Characteristics independently predicting recurrent HCM by multivariate logistic regression analysis.

\begin{tabular}{|c|c|c|c|c|c|}
\hline \multirow[b]{3}{*}{ Characteristics } & \multicolumn{3}{|c|}{ Univariate analysis } & & \\
\hline & \multicolumn{2}{|c|}{ Recurrent HCM, n (\%) } & \multirow[b]{2}{*}{ P-value } & \multicolumn{2}{|c|}{ Multivariate analysis } \\
\hline & Present & Absent & & Odds ratio $(95 \% \mathrm{CI})$ & P-value \\
\hline \multicolumn{6}{|l|}{ Age (years) } \\
\hline$\geq 61$ & $16(36.4)$ & $14(58.3)$ & 0.081 & Not applicable & \\
\hline$<61$ & $28(63.6)$ & $10(41.7)$ & & & \\
\hline \multicolumn{6}{|l|}{ Gender } \\
\hline Male & $32(72.7)$ & $14(58.3)$ & 0.225 & Not applicable & \\
\hline Female & $12(27.3)$ & $10(41.7)$ & & & \\
\hline \multicolumn{6}{|l|}{ Location of primary tumor } \\
\hline Right colon & $11(25.0)$ & $7(29.2)$ & 0.710 & Not applicable & \\
\hline Left colon & $33(75.0)$ & $17(70.8)$ & & & \\
\hline \multicolumn{6}{|l|}{ Size of primary tumor $(\mathrm{cm})$} \\
\hline$\geq 5$ & $23(52.3)$ & $9(37.5)$ & 0.243 & Not applicable & \\
\hline$<5$ & $21(47.7)$ & $15(62.5)$ & & & \\
\hline \multicolumn{6}{|l|}{ Histological grade } \\
\hline Well & $2(4.5)$ & $0(0.0)$ & 0.299 & Not applicable & \\
\hline Moderate & $41(93.2)$ & $23(95.8)$ & & & \\
\hline Poor & $1(2.3)$ & $1(4.2)$ & & & \\
\hline \multicolumn{6}{|l|}{ Pathological tumor stage } \\
\hline pT3 & $34(77.3)$ & $22(91.7)$ & 0.190 & Not applicable & \\
\hline pT4 & $10(22.7)$ & $2(8.3)$ & & & \\
\hline \multicolumn{6}{|l|}{ Nodal metastasis } \\
\hline Present & $36(81.8)$ & $13(54.2)$ & $0.015^{\mathrm{a}}$ & $4.690(1.168-18.826)$ & $0.029^{\mathrm{a}}$ \\
\hline Absent & $8(18.2)$ & $11(45.8)$ & & & \\
\hline \multicolumn{6}{|l|}{ TNM stage } \\
\hline II & $3(6.8)$ & $6(25.0)$ & 0.166 & Not applicable & \\
\hline III & $14(31.8)$ & $5(20.8)$ & & & \\
\hline IV & $27(61.4)$ & $13(54.2)$ & & & \\
\hline \multicolumn{6}{|l|}{ Lymphatic invasion } \\
\hline Present & $18(40.9)$ & $9(37.5)$ & 0.784 & Not applicable & \\
\hline Absent & $26(59.1)$ & $15(62.5)$ & & & \\
\hline \multicolumn{6}{|l|}{ Vascular invasion } \\
\hline Present & $11(25.0)$ & $1(4.2)$ & $0.045^{\mathrm{a}}$ & $5.088(0.486-53.282)$ & 0.175 \\
\hline Absent & $33(75.0)$ & $23(95.8)$ & & & \\
\hline \multicolumn{6}{|l|}{ Size of metastatic tumor $(\mathrm{cm})$} \\
\hline$\geq 2.5$ & $21(47.7)$ & $10(41.7)$ & 0.632 & Not applicable & \\
\hline$<2.5$ & $23(52.3)$ & $14(58.3)$ & & & \\
\hline \multicolumn{6}{|l|}{ No. of metastatic tumor } \\
\hline 1 & $18(40.9)$ & $20(83.3)$ & $0.034^{\mathrm{a}}$ & $9.893(2.413-40.565)$ & $0.001^{\mathrm{a}}$ \\
\hline 2 & $17(38.6)$ & $1(4.2)$ & & & \\
\hline 3 & $4(9.1)$ & $1(4.2)$ & & & \\
\hline$\geq 4$ & $5(11.4)$ & $2(8.3)$ & & & \\
\hline \multicolumn{6}{|c|}{ Distribution of metastatic tumor } \\
\hline Unilobar & $28(63.6)$ & $21(87.5)$ & $0.048^{\mathrm{a}}$ & $0.313(0.022-4.370)$ & 0.387 \\
\hline Bilobar & $16(36.4)$ & $3(12.5)$ & & & \\
\hline \multicolumn{6}{|l|}{ RKIP expression } \\
\hline Negative/weakly positive & $34(77.3)$ & $12(50.0)$ & $0.022^{\mathrm{a}}$ & $6.661(0.669-15.821)$ & $0.010^{\mathrm{a}}$ \\
\hline Positive & $10(22.7)$ & $12(50.0)$ & & & \\
\hline
\end{tabular}

${ }^{\mathrm{a}} \mathrm{P}<0.05$. 
Table IV. Combinations of independent predictive characteristics and probability of developing recurrent HCM.

\begin{tabular}{lllc}
\hline Nodal metastasis & No. of metastatic tumor & \multicolumn{1}{c}{ RKIP expression } & Probability of recurrent HCM \\
\hline Present & Multiple & Negative/weakly positive & 0.96 \\
Absent & Multiple & Negative/weakly positive & 0.84 \\
Present & Multiple & Positive & 0.81 \\
Present & Single & Negative/weakly positive & 0.74 \\
Absent & Multiple & Positive & 0.52 \\
Absent & Single & Negative/weakly positive & 0.48 \\
Present & Single & Positive & 0.39 \\
Absent & Single & Positive & 0.11 \\
\hline
\end{tabular}

survival rates $(18,23,34)$. However, despite the importance of $\mathrm{HCM}$ for the prognosis of CRC patients, no studies have been conducted regarding RKIP expression in HCM tissues or its prognostic significance.

Recurrence occurs in up to $70 \%$ of patients following hepatic resection for HCM, with the most common site being the liver. Approximately $25 \%$ of these patients have recurrence only in the liver and therefore may be suitable candidates for repeat hepatic resection (35). Previous studies have indicated that repeat hepatic resection for recurrent HCM yields comparable results to the first hepatic resection in terms of survival and operative mortality and morbidity $(14,36)$. Therefore, the ability to predict the risk of metastatic recurrence in HCM patients is of paramount importance because it may allow the identification of patients who should be monitored frequently and who could benefit from repeat hepatic resection. In this study, the combination of nodal metastasis, number of metastatic tumors and RKIP expression in HCM provided independent predictive information on the recurrence of HCM. These results agree with data from a large-scale study demonstrating that the presence of nodal metastasis and the multiplicity of HCM were independent predictors of poor outcome in HCM patients, and could be used as criteria for predicting metastatic recurrence (11). Surprisingly, in this study, the probability of developing recurrent HCM in patients with nodal metastasis, multiple HCMs and reduced RKIP expression was $96 \%$. In addition, the relative risk of recurrent HCM associated with reduction of RKIP expression was higher than the risk associated with nodal metastasis. Combined analysis of the independent predictors confirmed that the status of RKIP expression influences the probability of developing metastatic recurrence independent of nodal metastasis and number of metastatic tumor. Taken together, these results suggest that RKIP expression in CRC is a strong and novel predictive marker for the identification of patients at high risk of developing recurrent HCM and can be used as one of the criteria for predicting metastatic recurrence after hepatic resection in patients with HCM.

RKIP expression in HCM were associated with a shorter survival in HCM patients. There was a strong relationship between RKIP expression in HCM and survival even after adjusting for other prognostic parameters in the multivariate analysis, indicating that reduced RKIP expression in HCM is an independent predictor for poor prognosis. The absence of a significant relationship of RKIP expression in HCM with the established clinicopathological characteristics also indicated that RKIP expression in HCM is independent of other conventional prognostic parameters. Although previous studies have also shown RKIP expression to independently predict worse survival in CRC patients $(18,23)$, those studies used primary CRC tissues for immunostaining. This study shows that RKIP expression in HCM is an independent predictor for survival of HCM patients and suggests that RKIP expression in HCM can be used as a novel prognostic marker for worse outcome in HCM patients.

We observed that $22(32.4 \%)$ patients with HCM had positive RKIP expression. These findings are similar to data reported by previous studies $(20,22)$. There are several possible explanations for these results. First, the mechanisms causing metastasis are complex and multifactorial; a number of signaling pathways other than the ERK pathway can contribute to invasion and metastasis in CRC. Second, protein kinase C-mediated phosphorylation of RKIP results in the dissociation of RKIP from Raf-1 (37). Third, RKIP selectively impairs the phosphorylation of MEK by Raf-1; RKIP does not prevent the phosphorylation of MEK by kinases other than Raf-1 or by autophosphorylation. A recent study demonstrated that RKIP regulates Raf-1, but not B-Raf, suggesting that B-Raf can activate MEK and ERK independent of RKIP (38). Papin et al reported that B-Raf displayed a higher MEK kinase activity than Raf-1 (39). In addition to the predominant MEK activators Raf-1 and B-Raf, MEK kinase-1 (MEKK-1) and A-Raf can also phosphorylate MEK, although the biochemical potency of A-Raf is much weaker than that of Raf-1 or B-Raf (40). Finally, MEK is capable of autophosphorylation, leading to an increase of MEK kinase activity (41). These possibilities are currently being explored by evaluating the expression of protein kinase C, MEKK-1 and phosphorylated ERK and the mutational status of BRAF gene and by correlating them with RKIP expression in HCM.

Despite increasing evidence that RKIP is lost during tumor progression and especially in metastasis, the mechanism responsible for the downregulation of RKIP has yet to be elucidated. Some have suggested that RKIP promoter methylation is a potential RKIP silencing event, but these results are controversial. Minoo et al described RKIP methylation in a cohort of 12 patients with hyperplastic polyposis coli (42). In another study using CRC, however, the same authors failed to find RKIP methylation in all 28 cases examined (23). Al-Mulla et al reported that in CRC completely lacking 
Table V. Characteristics predicting worse OS by univariate and multivariate survival analyses.

\begin{tabular}{|c|c|c|c|c|c|}
\hline \multirow[b]{2}{*}{ Characteristics } & \multicolumn{3}{|c|}{ Univariate } & \multicolumn{2}{|l|}{ Multivariate } \\
\hline & $\begin{array}{l}\text { Median OS } \\
\text { (months) }\end{array}$ & $\begin{array}{l}\text { Standard error } \\
(95 \% \mathrm{CI})\end{array}$ & P-value & $\begin{array}{l}\text { Hazard ratio } \\
(95 \% \mathrm{CI})\end{array}$ & P-value \\
\hline \multicolumn{6}{|l|}{ Age (years) } \\
\hline$\geq 61$ & 34 & $4.19(25.78-42.22)$ & 0.446 & Not applicable & \\
\hline$<61$ & 65 & $16.27(33.11-96.89)$ & & & \\
\hline \multicolumn{6}{|l|}{ Gender } \\
\hline Male & 54 & $18.77(17.22-90.78)$ & 0.455 & Not applicable & \\
\hline Female & 45 & $12.03(21.43-68.57)$ & & & \\
\hline \multicolumn{6}{|l|}{ Location of primary tumor } \\
\hline Right colon & 40 & $11.74(17.00-63.00)$ & 0.773 & Not applicable & \\
\hline Left colon & 65 & $22.61(20.67-109.33)$ & & & \\
\hline \multicolumn{6}{|l|}{ Size of primary tumor $(\mathrm{cm})$} \\
\hline$\geq 5$ & 40 & $15.46(9.70-70.30)$ & 0.409 & Not applicable & \\
\hline$<5$ & 53 & $16.96(19.76-86.24)$ & & & \\
\hline \multicolumn{6}{|l|}{ Histological 1 grade } \\
\hline Well & 53 & Not available & 0.523 & Not applicable & \\
\hline Moderate & 45 & $11.76(21.95-68.05)$ & & & \\
\hline Poor & 26 & Not available & & & \\
\hline \multicolumn{6}{|l|}{ Pathological tumor stage } \\
\hline pT3 & 53 & $9.94(33.52-72.48)$ & 0.440 & Not applicable & \\
\hline pT4 & 32 & $20.04(0.00-71.27)$ & & & \\
\hline \multicolumn{6}{|l|}{ Nodal metastasis } \\
\hline Present & 44 & $11.35(21.75-66.25)$ & 0.081 & Not applicable & \\
\hline Absent & 72 & $32.43(8.44-135.56)$ & & & \\
\hline \multicolumn{6}{|l|}{ TNM stage } \\
\hline II & 130 & $41.43(48.79-211.21)$ & $0.008^{\mathrm{a}}$ & $5.247(1.615-17.043)$ & $0.006^{\mathrm{a}}$ \\
\hline III & 65 & $17.31(31.07-98.93)$ & & & \\
\hline IV & 35 & $12.05(11.39-58.61)$ & & & \\
\hline \multicolumn{6}{|l|}{ Lymphatic invasion } \\
\hline Present & 32 & $10.25(11.91-52.09)$ & $0.008^{\mathrm{a}}$ & $3.945(1.746-8.913)$ & $0.001^{\mathrm{a}}$ \\
\hline Absent & 72 & $12.02(48.45-95.55)$ & & & \\
\hline \multicolumn{6}{|l|}{ Vascular invasion } \\
\hline Present & 19 & $10.61(0.00-39.79)$ & $0.028^{\mathrm{a}}$ & $1.485(0.481-4.590)$ & 0.492 \\
\hline Absent & 54 & $15.17(24.27-83.73)$ & & & \\
\hline \multicolumn{6}{|l|}{ Size of metastatic tumor $(\mathrm{cm})$} \\
\hline$\geq 5$ & 54 & $21.54(11.78-96.22)$ & 0.626 & Not applicable & \\
\hline$<2.5$ & 44 & $12.85(18.81-69.19)$ & & & \\
\hline \multicolumn{6}{|l|}{ No. of metastatic tumor } \\
\hline 1 & 65 & $20.07(25.66-104.34)$ & $0.001^{\mathrm{a}}$ & $4.743(1.624-13.851)$ & $0.004^{\mathrm{a}}$ \\
\hline 2 & 35 & $1.94(31.21-38.79)$ & & & \\
\hline 3 & 20 & $7.42(5.46-34.54)$ & & & \\
\hline$\geq 4$ & 17 & $4.38(8.41-25.59)$ & & & \\
\hline \multicolumn{6}{|c|}{ Distribution of metastatic tumor } \\
\hline Unilobar & 53 & $12.61(28.28-77.72)$ & $0.047^{\mathrm{a}}$ & $2.482(1.194-5.160)$ & $0.015^{\mathrm{a}}$ \\
\hline Bilobar & 20 & $7.30(5.69-34.31)$ & & & \\
\hline \multicolumn{6}{|l|}{ Recurrent HCM } \\
\hline Present & 33 & $2.18(28.72-37.28)$ & $0.001^{\mathrm{a}}$ & $2.249(0.965-6.212)$ & 0.059 \\
\hline Absent & 72 & 4.17 (83.83-100.17) & & & \\
\hline \multicolumn{6}{|l|}{ RKIP expression } \\
\hline Negative/weakly positive & 35 & $7.89(19.53-50.47)$ & $0.009^{\mathrm{a}}$ & $5.161(1.267-13.882)$ & $0.014^{\mathrm{a}}$ \\
\hline Positive & 130 & $61.04(15.36-134.64)$ & & & \\
\hline
\end{tabular}

${ }^{\mathrm{a}} \mathrm{P}<0.05$. 
RKIP expression, the promoter region of RKIP was methylated, suggesting that CpG methylation of the RKIP promoter is a possible mechanism by which RKIP is silenced (17). In contrast, in a study using gastrointestinal stromal tumors, none of the cases without RKIP expression exhibited RKIP promoter methylation (43). Recently, SNAIL, a zinc finger transcriptional repressor gene, has been shown to bind to the E-box in the RKIP promoter and repress RKIP expression in a metastatic prostate carcinoma cell line (44). SNAIL is upregulated in human CRC and even more frequently overexpressed in tumors with metastatic ability (45). Therefore, further investigations exploring the possible association between RKIP and SNAIL in CRC should be performed.

In conclusion, we demonstrated that a reduction of RKIP expression in HCM had an independent predictive value for metastatic recurrence and less favorable clinical outcomes in patients with HCM. Patients harboring HCM with reduced RKIP expression require careful monitoring after hepatic resection for HCM for early detection of potentially resectable metastatic recurrences.

\section{References}

1. Calvert PM and Frucht H: The genetics of colorectal cancer. Ann Intern Med 137: 603-612, 2002.

2. Wang X, Wang Q, Hu W and Evers BM: Regulation of phorbol ester-mediated TRAF1 induction in human colon cancer cells through a PKC/RAF/ERK/NF-kappaB-dependent pathway. Oncogene 23: 1885-1895, 2004.

3. Fang JY and Richardson BC: The MAPK signalling pathways and colorectal cancer. Lancet Oncol 6: 322-327, 2005.

4. Yeung K, Seitz T, Li S, et al: Suppression of Raf-1 kinase activity and MAP kinase signalling by RKIP. Nature 401: 173-177, 1999.

5. Granovsky AE and Rosner MR: Raf kinase inhibitory protein: a signal transduction modulator and metastasis suppressor. Cell Res 18: 452-457, 2008.

6. Chatterjee D, Bai Y, Wang Z, et al: RKIP sensitizes prostate and breast cancer cells to drug-induced apoptosis. J Biol Chem 279: 17515-17523, 2004.

7. Woods Ignatoski KM, Grewal NK, Markwart SM, et al: Loss of Raf kinase inhibitory protein induces radioresistance in prostate cancer. Int J Radiat Oncol Biol Phys 72: 153-160, 2008.

8. Baritaki S, Katsman A, Chatterjee D, Yeung KC, Spandidos DA and Bonavida B: Regulation of tumor cell sensitivity to TRAILinduced apoptosis by the metastatic suppressor Raf kinase inhibitor protein via Yin Yang 1 inhibition and death receptor 5 up-regulation. J Immunol 179: 5441-5453, 2007.

9. Fu Z, Smith PC, Zhang L, et al: Effects of raf kinase inhibitor protein expression on suppression of prostate cancer metastasis J Natl Cancer Inst 95: 878-889, 2003.

10. Cunningham D, Pyrhonen S, James RD, et al: Randomised trial of irinotecan plus supportive care versus supportive care alone after fluorouracil failure for patients with metastatic colorectal cancer. Lancet 352: 1413-1418, 1998.

11. Fong Y, Fortner J, Sun RL, Brennan MF and Blumgart LH: Clinical score for predicting recurrence after hepatic resection for metastatic colorectal cancer: analysis of 1001 consecutive cases. Ann Surg 230: 309-318, 1999.

12. Nordlinger B, Vaillant JC, Guiguet M, et al: Survival benefit of repeat liver resections for recurrent colorectal metastases: 143 cases. Association Francaise de Chirurgie. J Clin Oncol 12: 1491-1496, 1994

13. DeMatteo RP, Fong Y, Jarnagin WR and Blumgart LH: Recent advances in hepatic resection. Semin Surg Oncol 19: 200-207, 2000.

14. Petrowsky H, Gonen M, Jarnagin W, et al: Second liver resections are safe and effective treatment for recurrent hepatic metastases from colorectal cancer: a bi-institutional analysis. Ann Surg 235: 863-871, 2002.

15. Bosman FT, Carneiro F, Hruban RH and Theise ND: WHO Classification of Tumours, Pathology and Genetics: Tumours of the Digestive System. IARC Press, Lyon, 2010.
16. Edge SB, Byrd DR, Compton CC, Fritz AG, Greene FL and Trotti A: AJCC Cancer Staging Manual. Springer, New York, NY, USA, 2010.

17. Al-Mulla F, Hagan S, Al-Ali W, et al: Raf kinase inhibitor protein: mechanism of loss of expression and association with genomic instability. J Clin Pathol 61: 524-529, 2008.

18. Al-Mulla F, Hagan S, Behbehani AI, et al: Raf kinase inhibitor protein expression in a survival analysis of colorectal cancer patients. J Clin Oncol 24: 5672-5679, 2006.

19. Kim HS, Kim GY, Lim SJ and Kim YW: Expression of Raf-1 kinase inhibitory protein in extrahepatic bile duct carcinoma. Korean J Pathol 44: 234-242, 2010.

20. Kim HS, Kim GY, Lim SJ and Kim YW: Loss of Raf-1 kinase inhibitory protein in pancreatic ductal adenocarcinoma. Pathology 42: 655-660, 2010.

21. Kim HS, Kim GY, Lim SJ and Kim YW: Raf-1 kinase inhibitory protein expression in thyroid carcinomas. Endocr Pathol 21: 253-257, 2010.

22. Kim HS, Kim GY, Lim SJ, Park YK and Kim YW: Reduced expression of Raf-1 kinase inhibitory protein is a significant prognostic marker in patients with gallbladder carcinoma. Hum Pathol 41: 1609-1616, 2010.

23. Minoo P, Zlobec I, Baker K, et al: Loss of raf-1 kinase inhibitor protein expression is associated with tumor progression and metastasis in colorectal cancer. Am J Clin Pathol 127: 820-827, 2007.

24. Schuierer MM, Bataille F, Weiss TS, Hellerbrand C and Bosserhoff AK: Raf kinase inhibitor protein is downregulated in hepatocellular carcinoma. Oncol Rep 16: 451-456, 2006.

25. Schuierer MM, Bataille F, Hagan S, Kolch W and Bosserhoff AK: Reduction in Raf kinase inhibitor protein expression is associated with increased Ras-extracellular signal-regulated kinase signaling in melanoma cell lines. Cancer Res 64: 5186-5192, 2004.

26. Li HZ, Wang Y, Gao Y, et al: Effects of raf kinase inhibitor protein expression on metastasis and progression of human epithelial ovarian cancer. Mol Cancer Res 6: 917-928, 2008.

27. Li HZ, Gao Y, Zhao XL, et al: Effects of raf kinase inhibitor protein expression on metastasis and progression of human breast cancer. Mol Cancer Res 7: 832-840, 2009.

28. Hu CJ, Zhou L, Zhang J, Huang C and Zhang GM: Immunohistochemical detection of Raf kinase inhibitor protein in normal cervical tissue and cervical cancer tissue. J Int Med Res 39: 229-237, 2011.

29. Hagan S, Al-Mulla F, Mallon E, et al: Reduction of Raf-1 kinase inhibitor protein expression correlates with breast cancer metastasis. Clin Cancer Res 11: 7392-7397, 2005.

30. Chen Y, Ouyang GL, Yi H, et al: Identification of RKIP as an invasion suppressor protein in nasopharyngeal carcinoma by proteomic analysis. J Proteome Res 7: 5254-5262, 2008.

31. Chatterjee D, Sabo E, Tavares R and Resnick MB: Inverse association between Raf Kinase Inhibitory Protein and signal transducers and activators of transcription 3 expression in gastric adenocarcinoma patients: implications for clinical outcome. Clin Cancer Res 14: 2994-3001, 2008.

32. Wang J, Yang YH, Wang AQ, et al: Immunohistochemical detection of the Raf kinase inhibitor protein in nonneoplastic gastric tissue and gastric cancer tissue. Med Oncol 27: 219-223, 2010.

33. Fu Z, Kitagawa Y, Shen R, et al: Metastasis suppressor gene Raf kinase inhibitor protein (RKIP) is a novel prognostic marker in prostate cancer. Prostate 66: 248-256, 2006.

34. Zlobec I, Baker K, Minoo P, Jass JR, Terracciano L and Lugli A: Node-negative colorectal cancer at high risk of distant metastasis identified by combined analysis of lymph node status, vascular invasion, and Raf-1 kinase inhibitor protein expression. Clin Cancer Res 14: 143-148, 2008.

35. Wanebo HJ, Chu QD, Avradopoulos KA and Vezeridis MP: Current perspectives on repeat hepatic resection for colorectal carcinoma: a review. Surgery 119: 361-371, 1996.

36. Adam R, Bismuth H, Castaing D, et al: Repeat hepatectomy for colorectal liver metastases. Ann Surg 225: 51-60, 1997.

37. Corbit KC, Trakul N, Eves EM, Diaz B, Marshall M and Rosner MR: Activation of Raf-1 signaling by protein kinase C through a mechanism involving Raf kinase inhibitory protein. J Biol Chem 278: 13061-13068, 2003.

38. Trakul N, Menard RE, Schade GR, Qian Z and Rosner MR: Raf kinase inhibitory protein regulates Raf-1 but not B-Raf kinase activation. J Biol Chem 280: 24931-24940, 2005. 
39. Papin C, Denouel-Galy A, Laugier D, Calothy G and Eychene A: Modulation of kinase activity and oncogenic properties by alternative splicing reveals a novel regulatory mechanism for B-Raf. J Biol Chem 273: 24939-24947, 1998.

40. Wu X, Noh SJ, Zhou G, Dixon JE and Guan KL: Selective activation of MEK1 but not MEK2 by A-Raf from epidermal growth factor-stimulated HeLa cells. J Biol Chem 271: 3265-3271, 1996.

41. Gardner AM, Vaillancourt RR, Lange-Carter CA and Johnson GL: MEK-1 phosphorylation by MEK kinase, Raf, and mitogen-activated protein kinase: analysis of phosphopeptides and regulation of activity. Mol Biol Cell 5: 193-201, 1994.
42. Minoo P, Baker K, Goswami R, et al: Extensive DNA methylation in normal colorectal mucosa in hyperplastic polyposis. Gut 55: 1467-1474, 2006

43. Martinho O, Gouveia A, Silva P, Pimenta A, Reis RM and Lopes JM: Loss of RKIP expression is associated with poor survival in GISTs. Virchows Arch 455: 277-284, 2009.

44. Beach S, Tang H, Park S, et al: Snail is a repressor of RKIP transcription in metastatic prostate cancer cells. Oncogene 27: 2243-2248, 2008.

45. Roy HK, Smyrk TC, Koetsier J, Victor TA and Wali RK: The transcriptional repressor SNAIL is overexpressed in human colon cancer. Dig Dis Sci 50: 42-46, 2005. 